\title{
How are we measuring health-related quality of life in patients with a Barrett Esophagus? A systematic review on patient-reported outcome measurements
}

\author{
Mirjam C. M. van der Ende-van Loon ${ }^{1}$ (1) - A. Stoker ${ }^{1}$ - P. T. Nieuwkerk ${ }^{2} \cdot$ W. L. Curvers ${ }^{1} \cdot$ E. J. Schoon ${ }^{1,3}$
}

Accepted: 28 September 2021 / Published online: 8 November 2021

(c) The Author(s) 2021

\begin{abstract}
Purpose Barrett esophagus (BE) is associated with a significant decrease of health-related quality of life (HRQoL). Too often, patient-reported outcome measures (PROMs) are applied without considering what they measure and for which purposes they are suitable. With this systematic review, we provide researchers and physicians with an overview of all the instruments previously used for measuring HRQoL in BE patients and which PROMs are most appropriate from the patient's perspective. Methods A comprehensive search was performed to identify all PROMs used for measuring HRQoL in BE patients, to identify factors influencing HRQoL according to BE patients, and to evaluate each PROM from a patients' perspective.

Results Among the 27 studies, a total of 32 different HRQoL instruments were identified. None of these instruments were designed or validated for use in BE patients. Four qualitative studies were identified exploring factors influencing HRQoL in the perceptions of BE patients. These factors included fear of cancer, anxiety, trust in physician, sense of control, uncertainty, worry, burden of endoscopy, knowledge and understanding, gastrointestinal symptoms, sleeping difficulties, diet and lifestyle, use of medication, and support of family and friends.

Conclusion None of the quantitative studies measuring HRQoL in BE patients sufficiently reflected the perceptions of HRQoL in BE patients. Only gastrointestinal symptoms and anxiety were addressed in the majority of the studies. For the selection of PROMs, we encourage physicians and researchers measuring HRQoL to choose their PROMs from a patient perspective and not strictly based on health professionals' definitions of what is relevant.
\end{abstract}

Keywords Barrett Esophagus · Quality of life · Patient-reported outcome measures · PROM

PROSPERO database nmr CRD42021224231.

Mirjam C. M. van der Ende-van Loon

mirjam.vd.ende@catharinaziekenhuis.nl

A. Stoker

Annemay.stoker@catharinaziekenhuis.nl

P. T. Nieuwkerk

p.t.nieuwkerk@amsterdamumc.nl

W. L. Curvers

wouter.curvers@catharinaziekenhuis.nl

E. J. Schoon

erik.schoon@catharinaziekenhuis.nl

1 Department of Gastroenterology and Hepatology, Catharina Hospital, Michelangelolaan 2, 5623 EJ Eindhoven, The Netherlands

2 Department of Medical Psychology, Academic Medical Center, Amsterdam, The Netherlands

3 GROW: School of Oncology and Developmental Biology, Maastricht University, Maastricht, The Netherlands

\section{Introduction}

Barrett's esophagus (BE) is a premalignant condition involving metaplastic transformation of the lower esophageal lining from squamous to intestinal epithelium, due to gastroesophageal reflux disease (GERD) [1, 2]. BE is associated with an increased risk of an esophageal adenocarcinoma (EAC). The relative risk of EAC in patients with non-dysplastic BE is $30-125$ times higher compared to the general population. Patients therefore undergo regular endoscopic surveillance for early detection of malignant transformation. Although early detection may lead to improved survival, the absolute risk for malignant transformation is low (approximately $0.3-0.5 \%$ per year) $[3,4]$ and the efficacy of surveillance and the influence of BE on life expectancy are still questioned [4-7]. The effect of endoscopic surveillance programs on patient's perspective and quality of life should, therefore, not be neglected [8]. 
$\mathrm{BE}$ is associated with a significant decrease of healthrelated quality of life (HRQoL), measured with both generic and disease-targeted instruments [9]. In addition, patients with BE are at risk for psychological consequences such as depression, anxiety, and stress. These negative effects of BE on HRQoL and psychological health may be related to patients' perception of the risk of developing EAC [9]. HRQol is generally considered to encompass patients' physical, psychological, and social functioning, which can be affected by both the disease and treatment [10].

Nowadays, there is an increased awareness in international health care policy on the importance of measuring quality of care. Patient-reported outcomes (PRO) are an important instrument for measuring quality of care, enabling improvement and transparency in health care. The choice of what to measure (PRO) and how to measure is a complicated but important process. Too often, patient-reported outcome measurements (PROMs) are applied without considering what they should measure and for which purposes they are suitable. There is a rapid increase of questionnaires to choose from, however, it is often not clear which one is the best given its purpose. Currently, there is no BE-specific PROM available.

In this systematic review, we will identify all PROMs used for measuring HRQoL in BE patients, identify factors influencing HRQoL according to BE patients, and evaluate each PROM from a patient's perspective. This systematic review is part of a research project on the development of a person-centered measurement tool, measuring HRQoL in BE patients.

\section{Materials and methods}

This systematic review was performed in accordance with the preferred reporting items for systematic reviews and meta-analyses (PRISMA) statement [11].

\section{Literature search}

Two independent researchers (MvdE and AS) independently conducted a systematic search from inception to February 1, 2021 in the following electronic databases: Pubmed, EMBASE, CINAHL, and PsycINFO. To search the databases, we used medical subject headings (MeSH) and freetext words (Fig. 1). We additionally carried out reference and citation searches of all included articles and relevant review articles.

\section{Inclusion and exclusion criteria}

Studies were included when they were written in English and included only patients over 18 years old. Each article was judged against two sets of inclusion criteria (Fig. 1).

(1) Studies using HRQoL PROMs were included when they met the following criteria:

(a) Using one or more PROMs for assessing HRQoL in BE patients. A PROM was defined as any selfadministered QOL instrument assessing one of the three core domains described by the World Health Association: physical, social, and psychological wellbeing [12].

(b) Measuring HRQoL in patients with a study population containing more than $25 \%$ BE patients. With this criterion, we aimed to ensure that the authors chose their PROMs from a perspective of the BE population. Subsequently, we used a criterion of inclusion of $n>25$ to guarantee an acceptable quality of the included articles with a quantitative approach.

Studies with primarily post-surgery measurements were excluded.

(2) Studies on influencing factors were included when they met the following criteria:

(a) Using a qualitative methodology (e.g., focus groups or in-depth interviews).

(b) Studies including only BE patients.

\section{Data extraction and analysis}

\section{(1) Identification of PROMs}

The details of all included studies (e.g., aim, sample sizes, study objectives, the level of evidence according to the Oxford Centre for Evidence-Based Medicine (OCEBM) criteria [13], and the PROMs used for measuring HRQoL) were reported in a summary table. Subsequently, it was determined whether a validation in the BE population was described in the reference literature of the included articles. Objectives and domains of each PROM were obtained. PROMs measuring perceived cancer risk, time trade-off, and standard gamble scores were not used for analyses. 


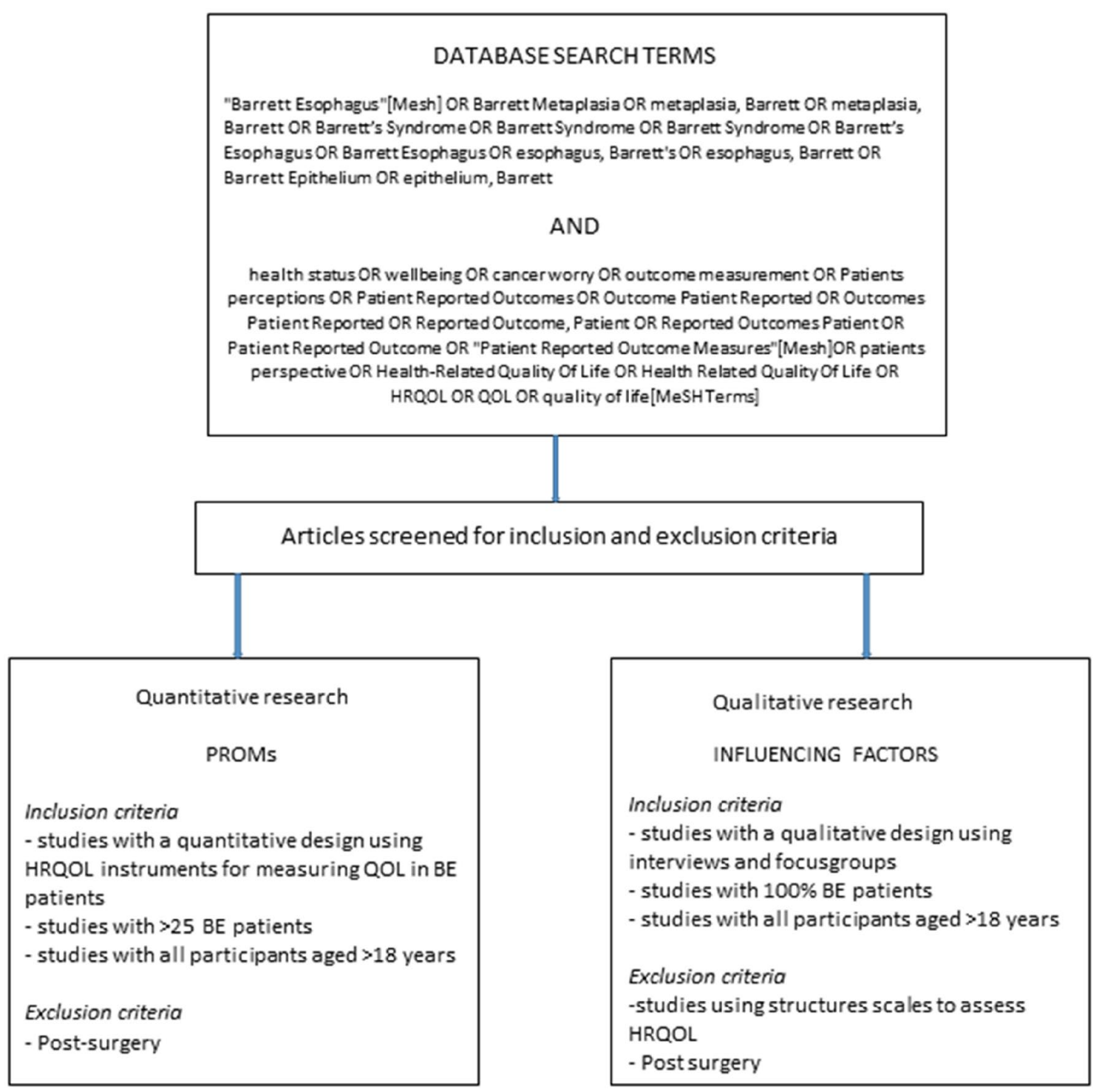

Fig. 1 Database search in- and exclusion criteria

(2) Identification of influencing factors according to BE patients

To identify factors influencing HRQoL according to BE patients, quality assessment was independently conducted by two researchers (MvdE and AS) using the Critical Appraisal Skills Programme (CASP) criteria; a 10-item checklist designed for use in the appraisal of qualitative research studies [14]. In addition, factors were evaluated according to their relevance. To evaluate intra-rater and inter-rater reliability in the factors extracted from the literature review, two reviewers (MvdE and AS) each independently extracted a list of potential factors from the articles included. The two lists were compared, and differences resolved by consensus. All influencing factors identified were categorized into domains according to the patient-reported outcomes measurement information system (PROMIS) Adult Self-Reported Health model [15]. 


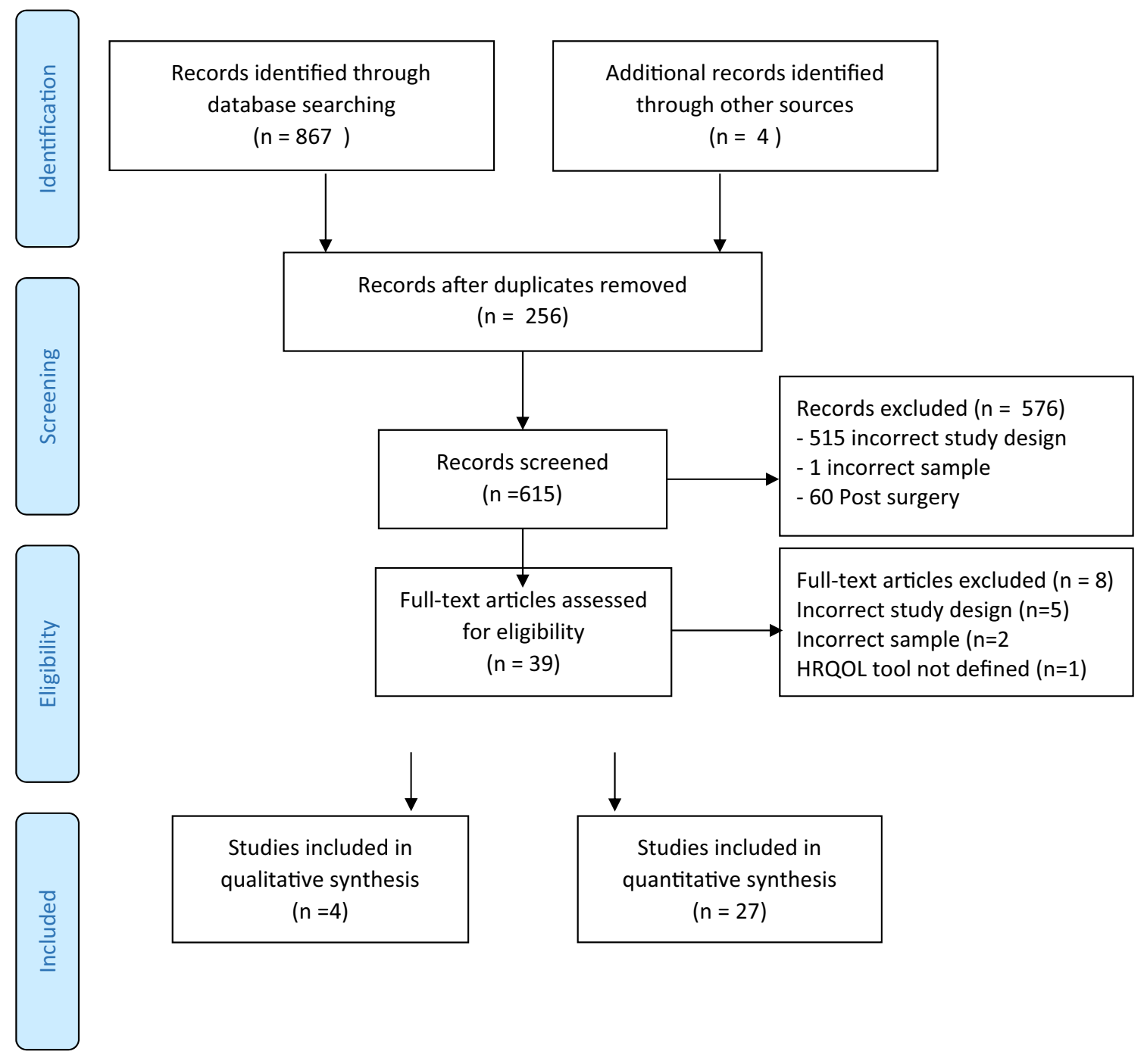

Fig. 2 PRISMA 2009 Flow diagram

\section{(3) Evaluation of each PROM}

Finally, each PROM was evaluated in terms of its ability to capture factors important to BE patients. For each factor, it was examined whether this was measured with an item of the PROM. A distinction was made between addressing a factor directly or indirectly in an item of the questionnaire. For example, when a questionnaire inquired about pain in general, the factor epigastric pain was considered to be measured indirectly.

\section{Results}

The literature search identified 402 articles. Twenty-seven articles met the inclusion criteria for HRQoL PROMs, after manual review of the full texts, and were included for analysis. Four qualitative studies that met the criteria for influencing factors were included (Fig. 2). 


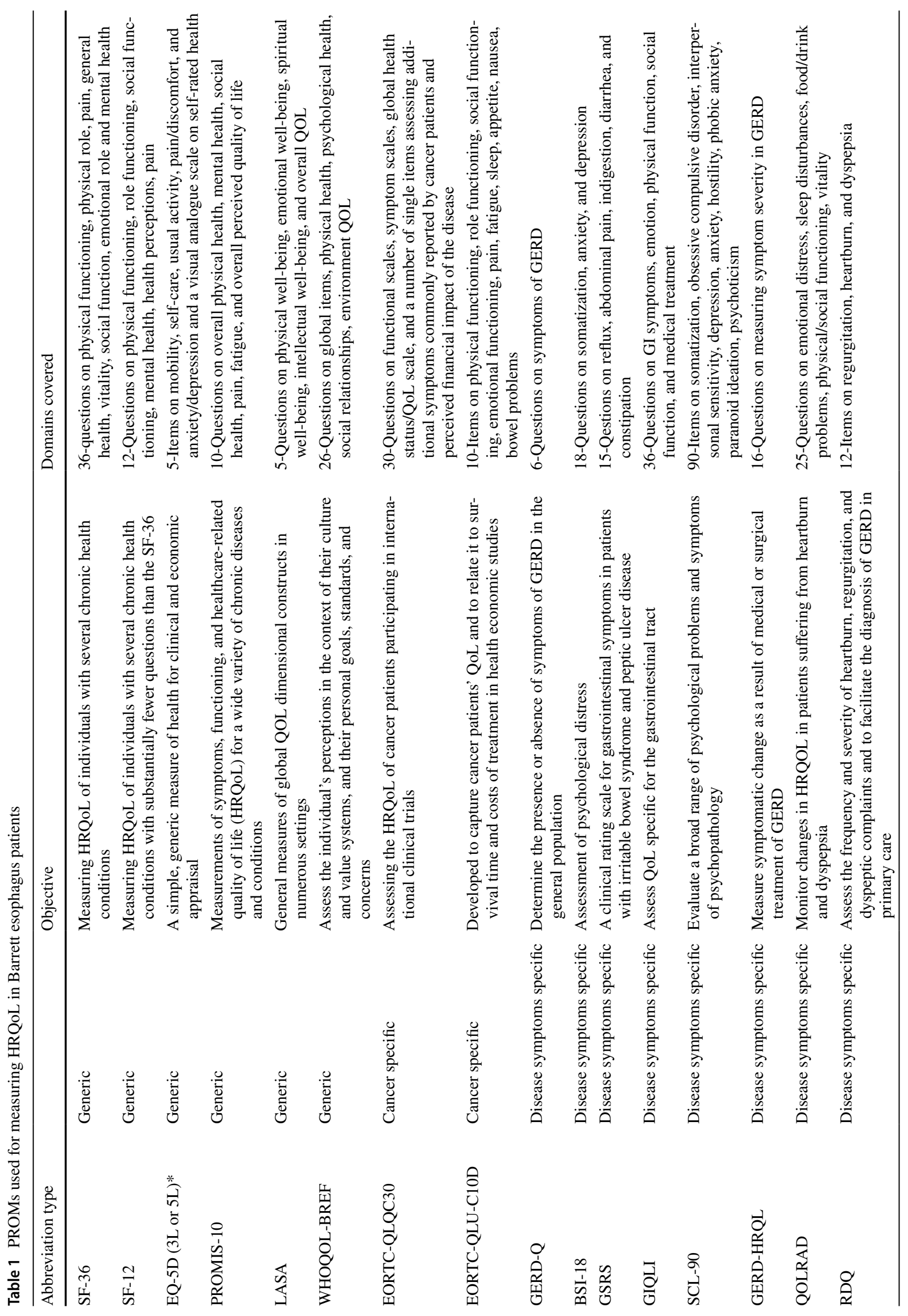




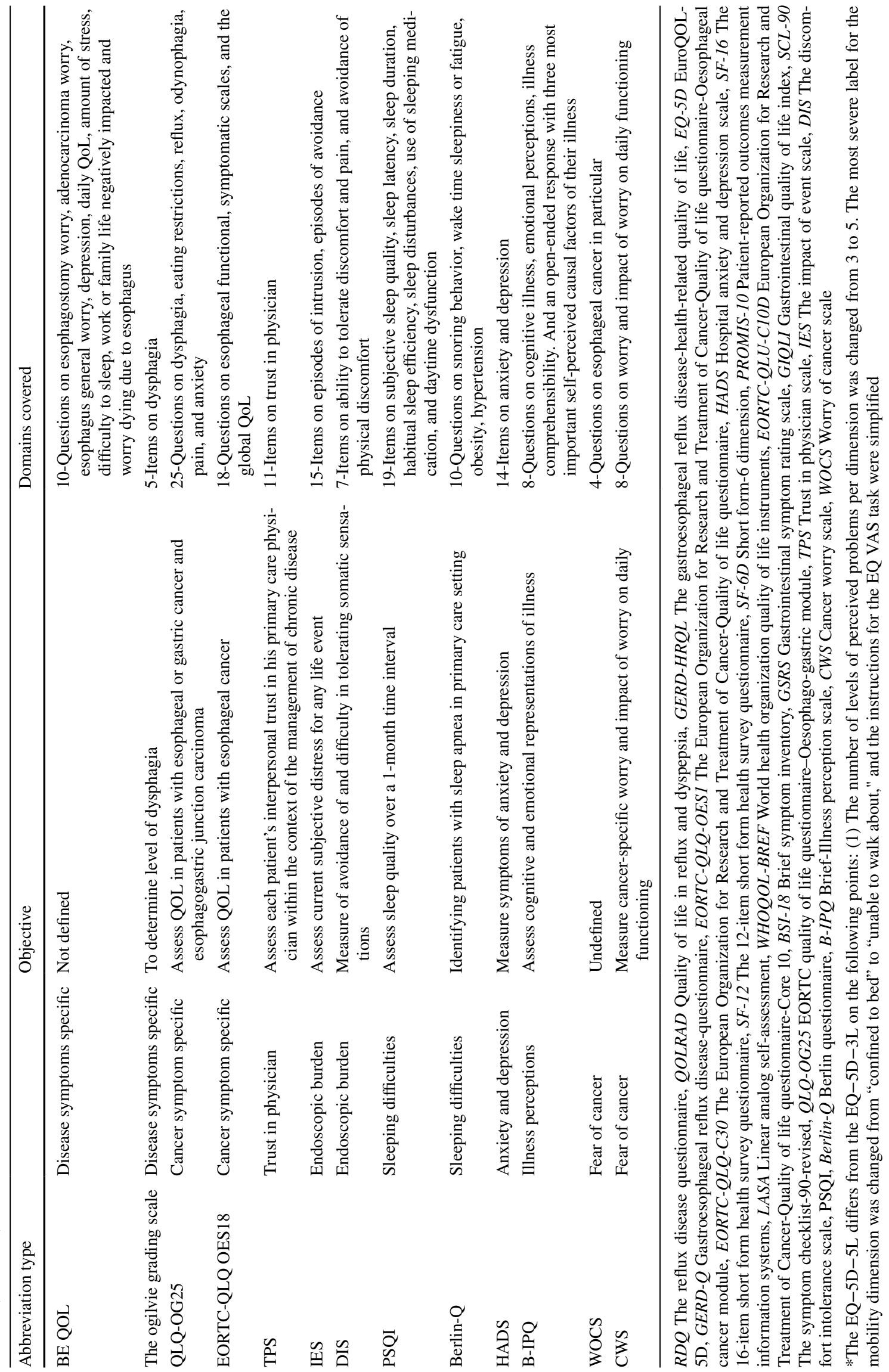




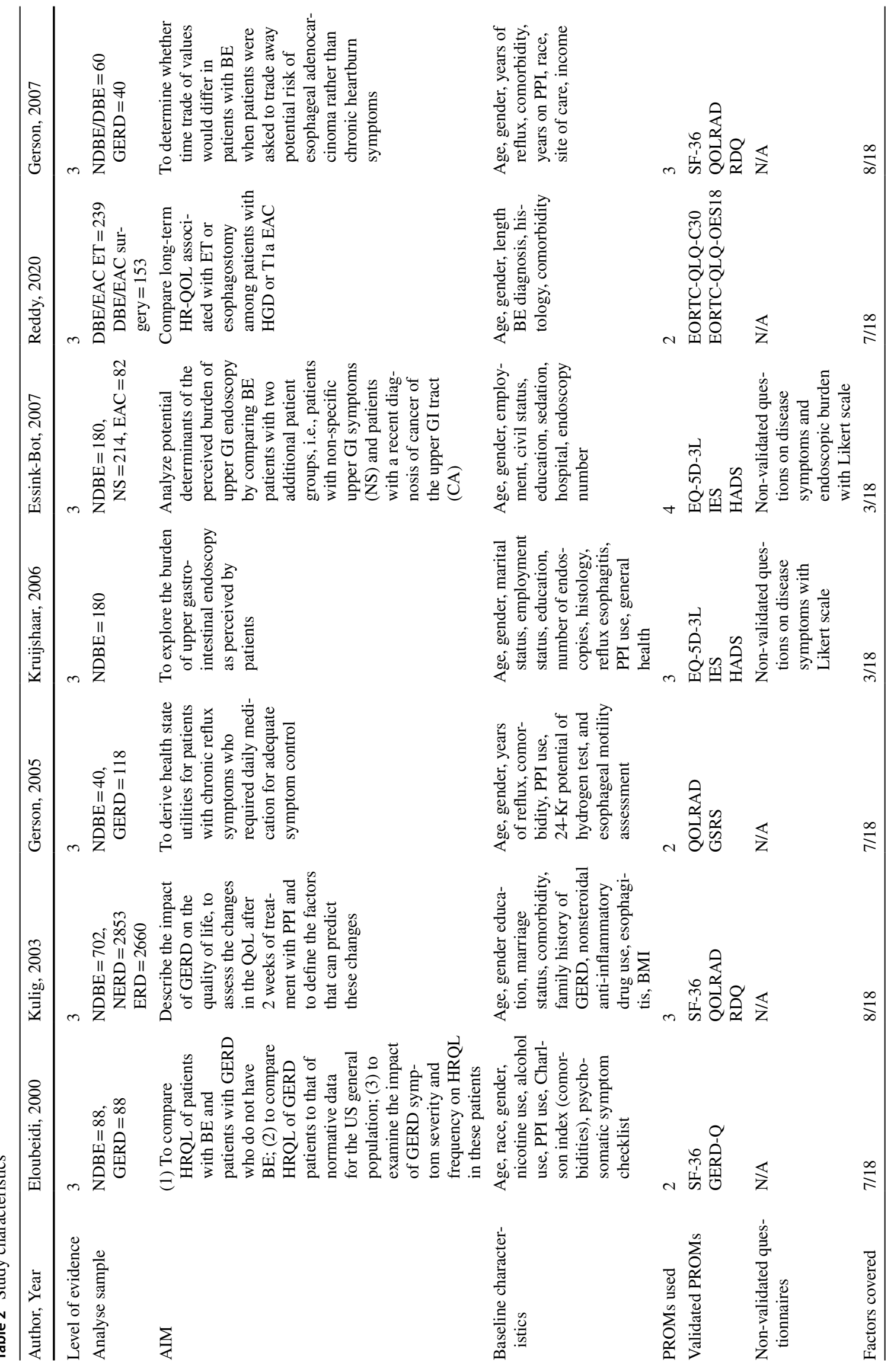




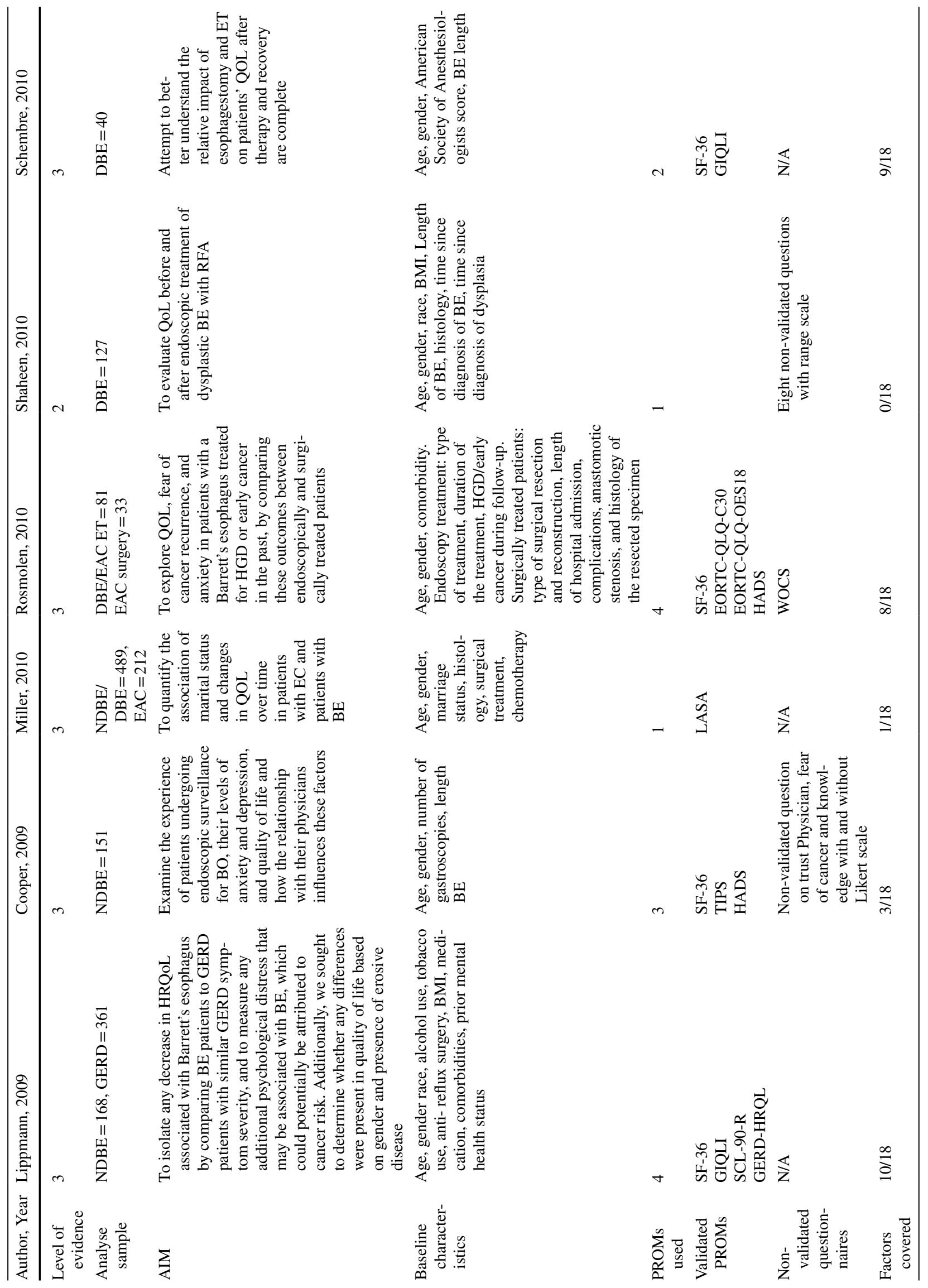




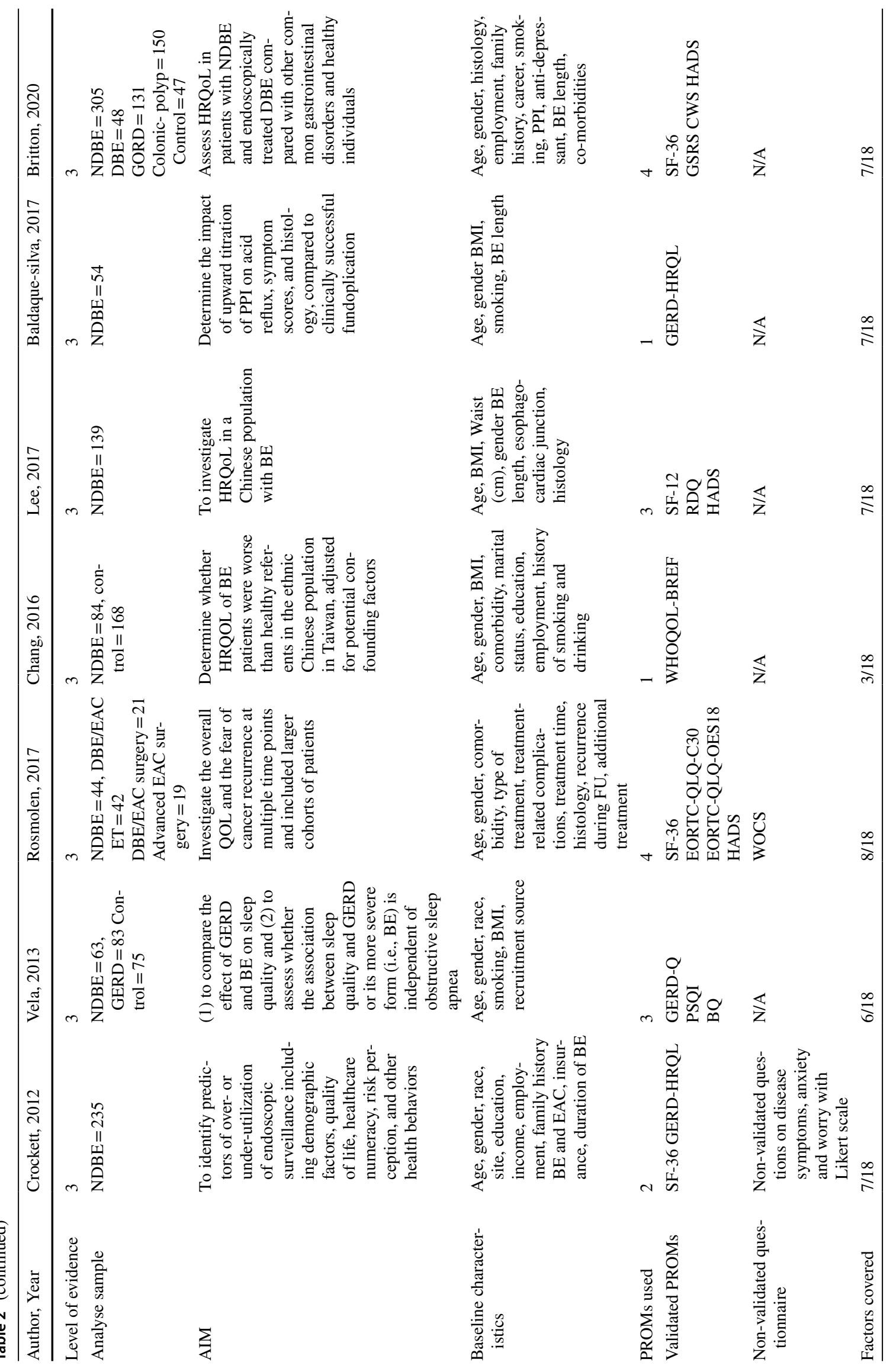




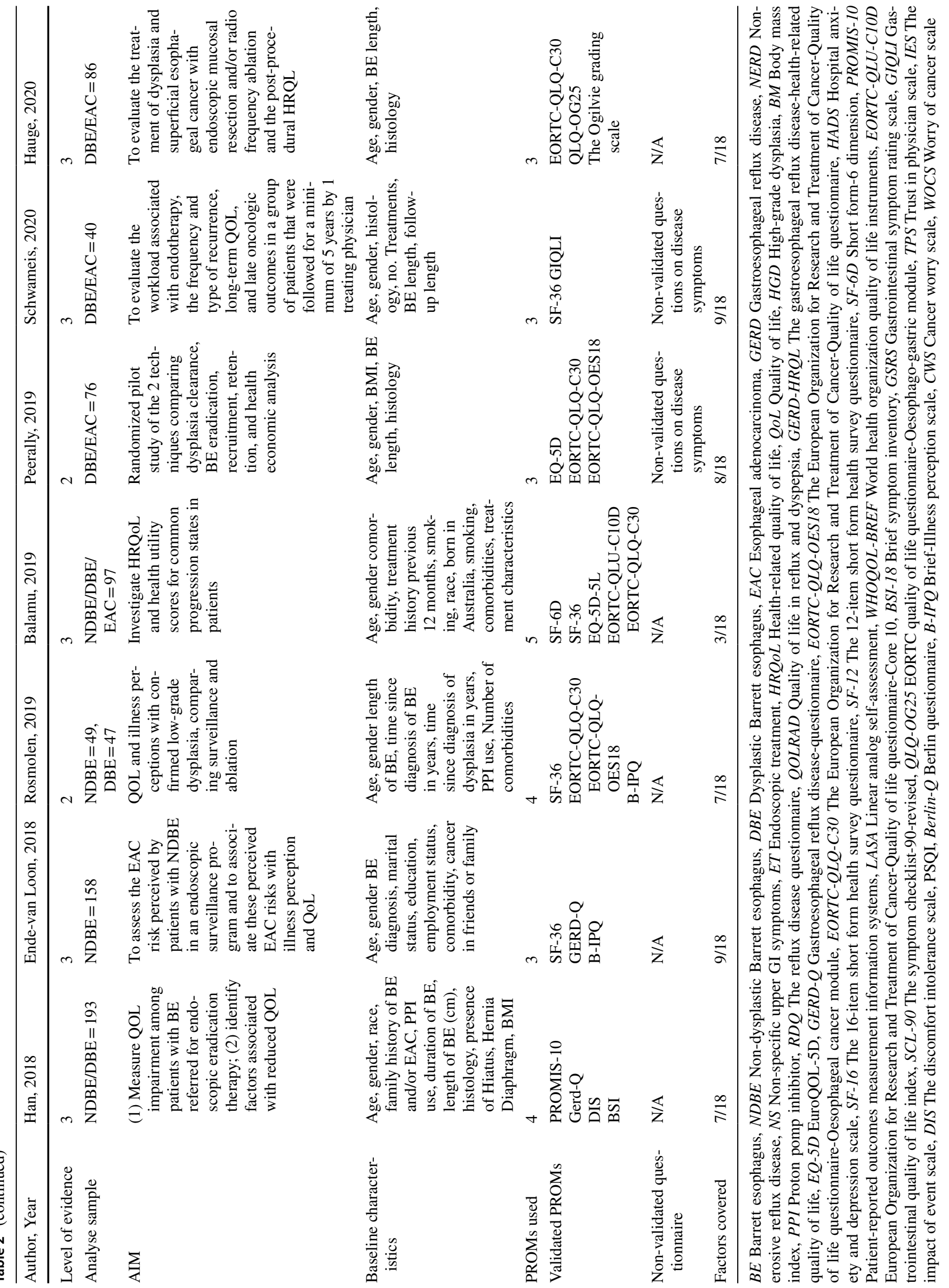


Fig. 3 Top 10 most frequently reported PROMs

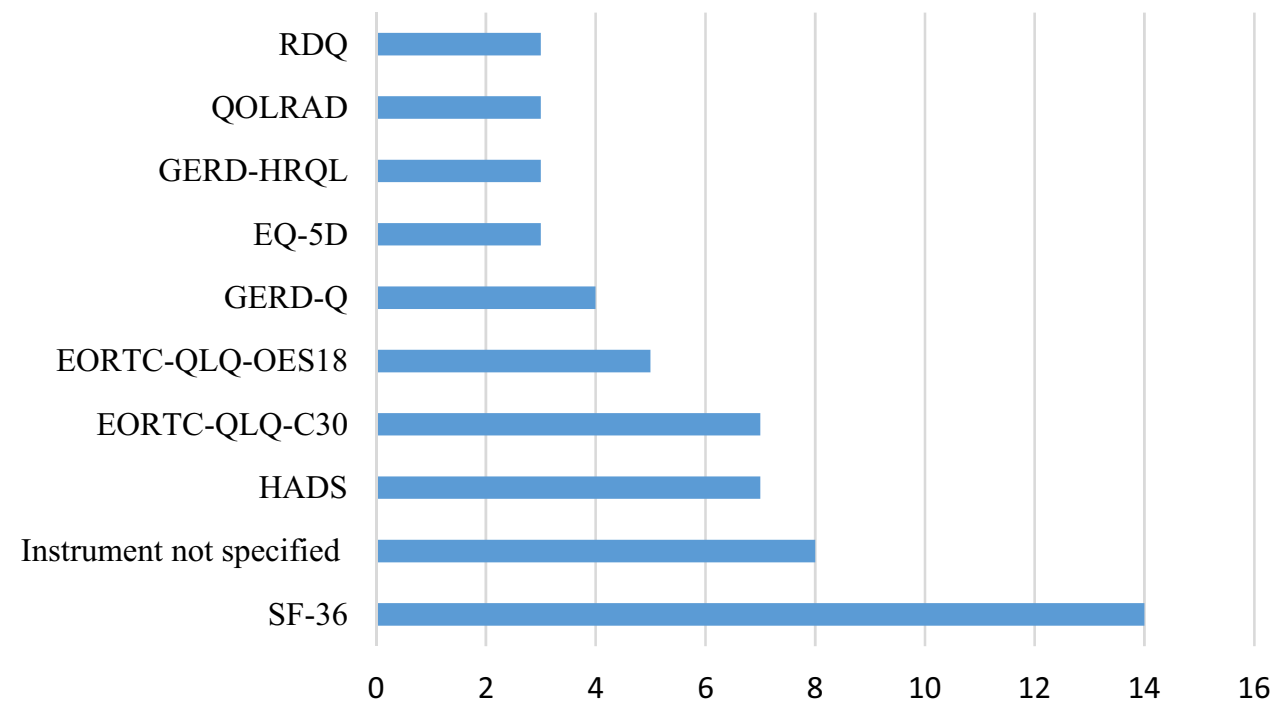

\section{Identification of PROMs}

Among the 27 studies [16-42], 32 different PROMs (Table 1) were identified. A total of nine studies [16, 21, 22, 31, 34, 35, 40-42] used PROMs that were not formally validated.

The study of Shaheen et al. [31] used a disease-specific $\mathrm{BE}$ questionnaire. However, to our knowledge, this specific $\mathrm{BE}$ questionnaire has not been properly validated.

An average of 3 (range 1-5) PROMs per study were used. Table 2 demonstrates a summary of sample and design characteristics of studies reporting HRQoL in BE patients. The mean number of PROMs used per study did not change over the years. Three Level 2 studies were found using PROMs in a RCT design. The majority (87.9\%) were Level 3 studies per OCEBM criteria [13].

Seven different PROMs were used for measuring generic HRQoL (SF-36, SF-12, SF-6D, WHOQOL-BREF, LASA, PROMIS-10, and the EQ-5D for measuring health utility). Two disease-specific PROMs assessed the generic aspects of QOL in cancer patients (EORTC-QLQC30 and QLUC10D). Fourteen different disease-specific PROMs were used, measuring symptoms related to BE (GERD-Q, GERDHRQL, BSI, GSRS, GIQLI, SCL-90, QOLRAD, RDQ, EORTC-QLQOES18, QLQ-OG25, the EORTC-QLQ OES, QLQ-OG25 and five different non-validated questionnaires) $[16,34,35,40,41]$. Cancer worry was measured with the WOCS, CWS, and a non-validated questionnaire [42].

Two PROMs measured sleeping difficulties (PSQI, $B Q)$. Endoscopic burden was measured with three different PROMs (IES, DIS, and a non-validated Likert scale questionnaire [41]). An additional number of PROMs were identified, measuring trust in physician using the trust in physician scale (TIPS), anxiety and depression (HADS and a non-validated Likert questionnaire) [34], illness perceptions (B-IPQ), knowledge with non-validated questionnaire [42], and trust in the endoscopy with a non-validated Likert questionnaire [42]. The 10 most frequently cited PROMs are illustrated in Fig. 3. All studies except four [24, 26, 31, 36] used some form of a generic PROM for measuring HRQoL. The SF-36 was utilized most often, respectively, in 51.8\% of the studies. Symptoms related to BE were measured in $85.2 \%$ of studies. The EORTC-QLQ-OES18, GERD-Q, QOLRAD, RDQ, and GERD-HRQL were most frequently used to measure reflux symptoms. Non-validated questionnaires were used in $30 \%$ of all included studies.

\section{Identification of influencing factors according to BE patients}

Four studies with a qualitative design were identified: one study used a focus group design and three used patient interviews [43-46]. The study characteristics and quality scores are demonstrated in Table 3. Studies were published between 2011 and 2020 and were conducted in the UK $(n=2)$, USA $(n=1)$, and the Netherlands $(n=1)$. All studies showed a minimal quality score of $7 / 10$ according to CASP [14]. Within these studies, the following factors related to HRQoL according to BE patients were identified, namely fear of cancer, anxiety, trust in physicians, sense of control, uncertainty, worry, burden of endoscopy, knowledge and understanding, gastrointestinal (GI) symptoms (e.g., reflux or heartburn, regurgitation, dyspepsia, dysphagia, epigastric pain), sleeping difficulties, diet and lifestyle, use of medication, and 


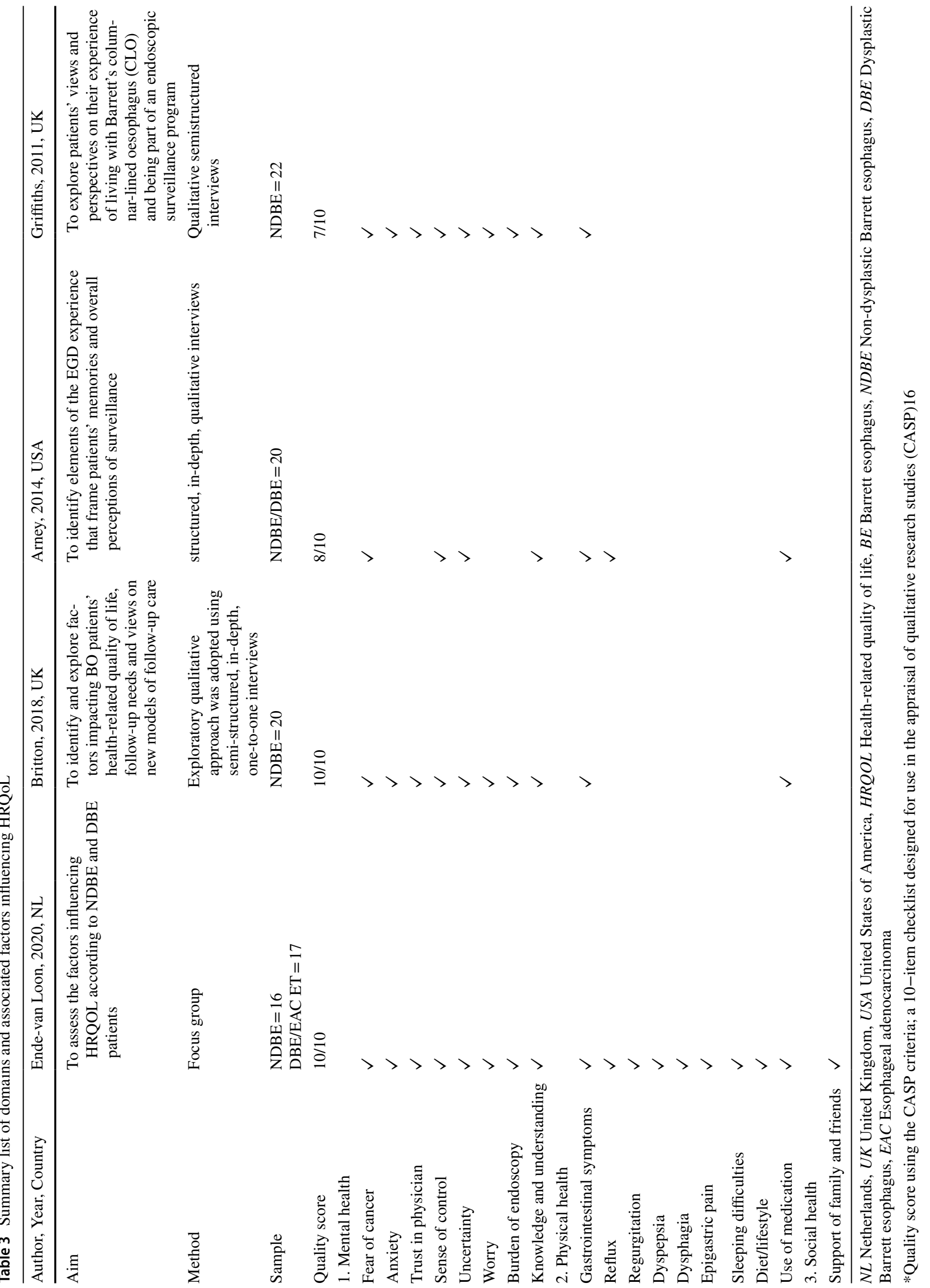


support of family and friends. These factors were allocated into domains and displayed in a conceptual framework (see Fig. 4).

\section{Coverage of factors in HRQOL PROMs relevant to patients}

None of the 27 identified PROMs covered all factors important to BE patients (Table 4). Generic PROMs were used in $77.8 \%$ of all studies, and only a small number of factors were indirectly addressed. For instance, the commonly used SF 36 and SF12 contained items indirectly addressing anxiety and items on pain in general. The EQ-5D, PROMIS 10, LASA, WHOQOL-BREF had additional items on anxiety, and the EORTC-QLQC30 on worry.

The cancer-specific PROMs (EORTC-QLQ C30, EORTC-QLQ C10D) and the generic WHOQOL-BREF measured items of sleeping difficulties in addition to anxiety and pain and indirectly addressed the burden of the use of medication.

Looking at more disease-specific measures, we found that the GIQLI, GERD-HRQL covered all factors related to GI symptoms. Furthermore, the GERD-HRQL addressed an item on lifestyle, whereas the GIQLI contained an item on support of family.

The EORTC-QLQ-OES18 was the only PROM with items on diet and lifestyle; this factor was only indirectly addressed by the GERD-HRQL and the QOLRAD. The other cancer-specific PROM, the QLQ-OG25, addressed GI symptoms, as well as anxiety and worry. The factors 'sense of control' and 'knowledge and understanding' were measured by items of the B-IPQ. Although fear of cancer was stated as an important factor influencing HRQoL in the literature, it was only measured in one study using the CWS [38]. In another study by Rosmolen et al. [21, 22], the WOCS was used for assessing fear of cancer (recurrence). However, we found no accurate validation in the references.

The TPS was the only PROM measuring 'trust in the physician.' The factors uncertainty (QOLRAD) and endoscopic burden (IES) were only indirectly assessed. No PROMs with items on measuring the factor endoscopy as safety net were found. None of the studies address more than nine of the 18 factors important to patients with BE. Overall, a median of 7 (0-9) factors, stated as important to patients using validated PROMs, were covered.

\section{Discussion}

In this systematic review, we identified 27 studies measuring HRQoL in BE patients; within these studies, 32 different PROMs were used. None of the identified PROMs were specifically validated to measure $\mathrm{HRQoL}$ in BE patients. Consequently, we found that a total of nine studies (33.3\%) used some form of non-validated questionnaires. It is interesting to note that the total number of interventional studies that used HRQoL measurements is relatively low. These findings are in contrast with the increased number of endoscopic therapeutic options for BE patients resulting in publications [47].

The most frequently used PROMs for measuring generic HRQoL was the SF-36 (52.2\%). Symptoms related to BE were frequently $(83.4 \%)$ measured by the EORTC-QLQOES18, GERD-Q, GERD-HRQOL, QOLRAD, and the RDQ. The HADS was used to measure symptoms of anxiety and depression in $26 \%$ of studies.

We identified four studies with a qualitative design exploring factors influencing HRQoL according to $\mathrm{BE}$ patients. Within these studies, the following factors were addressed, namely fear of cancer, anxiety, trust in physician, sense of control, uncertainty, worry, burden of endoscopy, knowledge and understanding, GI symptoms, sleeping difficulties, diet and lifestyle, use of medication, and support of family and friends. These findings are fairly in line with those of Britton et al. [8]. In this study, symptom control, psychological effects as anxiety and depression, worry of cancer, patients' subjective perceived risk of cancer, frequency and severity of worry, and disease-specific knowledge were considered key factors for assessing HRQoL in BE patients.

None of the studies addressed more than nine of the 18 factors important to patients with BE. Disease-specific PROMs were more successful in covering factors important to BE patients, compared to generic PROMs. Interestingly, generic PROMs were used in $77.8 \%$ of all studies. However, generic PROMs are used to provide comparisons between diseases or to compare data with population normative values, not to evaluate specific patient populations. The selection of PROMs is a complex but essential process. Several documents for guidance in the appropriate selection of PROMs in clinical trials are available [48]. The current review confirms the need of a more patientcentered approach in measuring HRQoL in BE patients. Since there is no BE-specific PROM available, the development of a new instrument seems inevitable. However, a wide variety of PROMs is currently available, and the development of a new measurement tool is time-consuming and complex. A combination of the following disease-specific PROMs GIQLI or GERD-HRQOL, with the CWS, TPS, the B-IPQ would be appropriate to measure factors influencing HRQoL in BE patients. This would, however, necessitate a large number of questions to be addressed by patients. Using the "Patient-Reported Outcomes Measurement Information System" (PROMIS) databank may be 


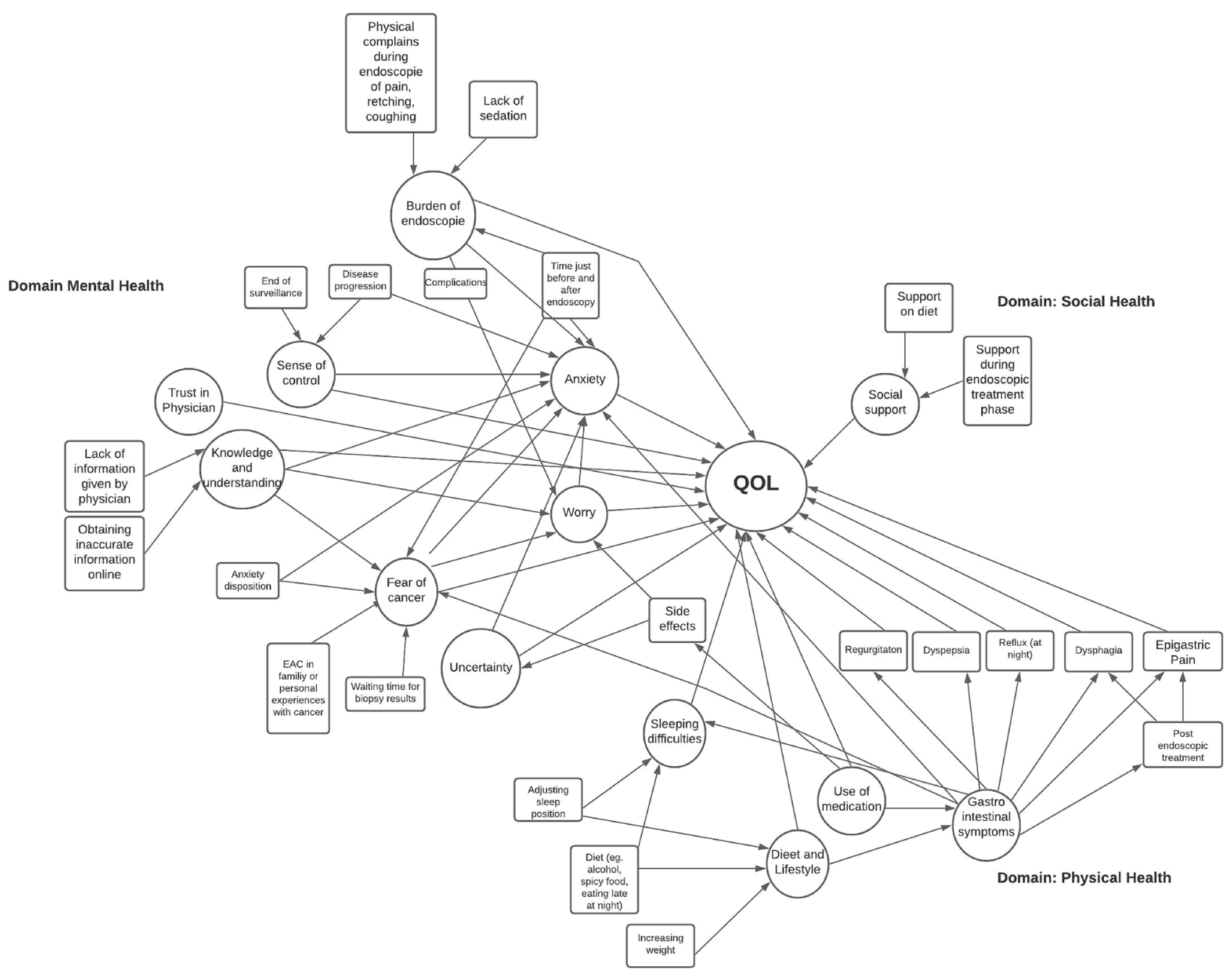

Fig. 4 Conceptuel framework

an appropriate solution for this problem. PROMIS is an easily accessible set of person-centered measures, using computerized adaptive testing from large item banks for over 70 domains relevant to a wide variety of chronic diseases [49-51]. PROMIS enables comparisons across populations and studies and can be integrated in several electronic health records. We advise clinicians to use the items: PROMIS ${ }^{\circledR}$ GI (disrupted and swallowing, reflux and gas and bloating), PROMIS $®$ Anxiety, and PROMIS ${ }^{\circledR}$ Self-Efficacy (Managing medications and treatment, Managing Symptoms). Further research is needed to validate the PROMIS databank in BE patients.

The current study has some limitations that need to be addressed. First, the aim of this review was to identify studies that measure HRQoL in BE patients. Using MeSH and free-text words focusing on areas of HRQoL, we may have underestimated the number of interventional studies that used HRQoL as a secondary endpoint. Second, we identified only four studies with a qualitative study design. Of these, two studies directly investigated factors important to BE patients, while the other two used an indirect manner by focusing on patients experiences with surveillance endoscopy and patient burden, care delivery experience, and follow-up needs. However, all factors identified in the latter two studies were confirmed in the first two studies. Third, the list of factors important to BE patients and the degree to which factors were addressed by the various PROMs is subjective. To increase the intra-rater and inter-rater reliability, 
Quality of Life Research (2022) 31:1639-1656

1653

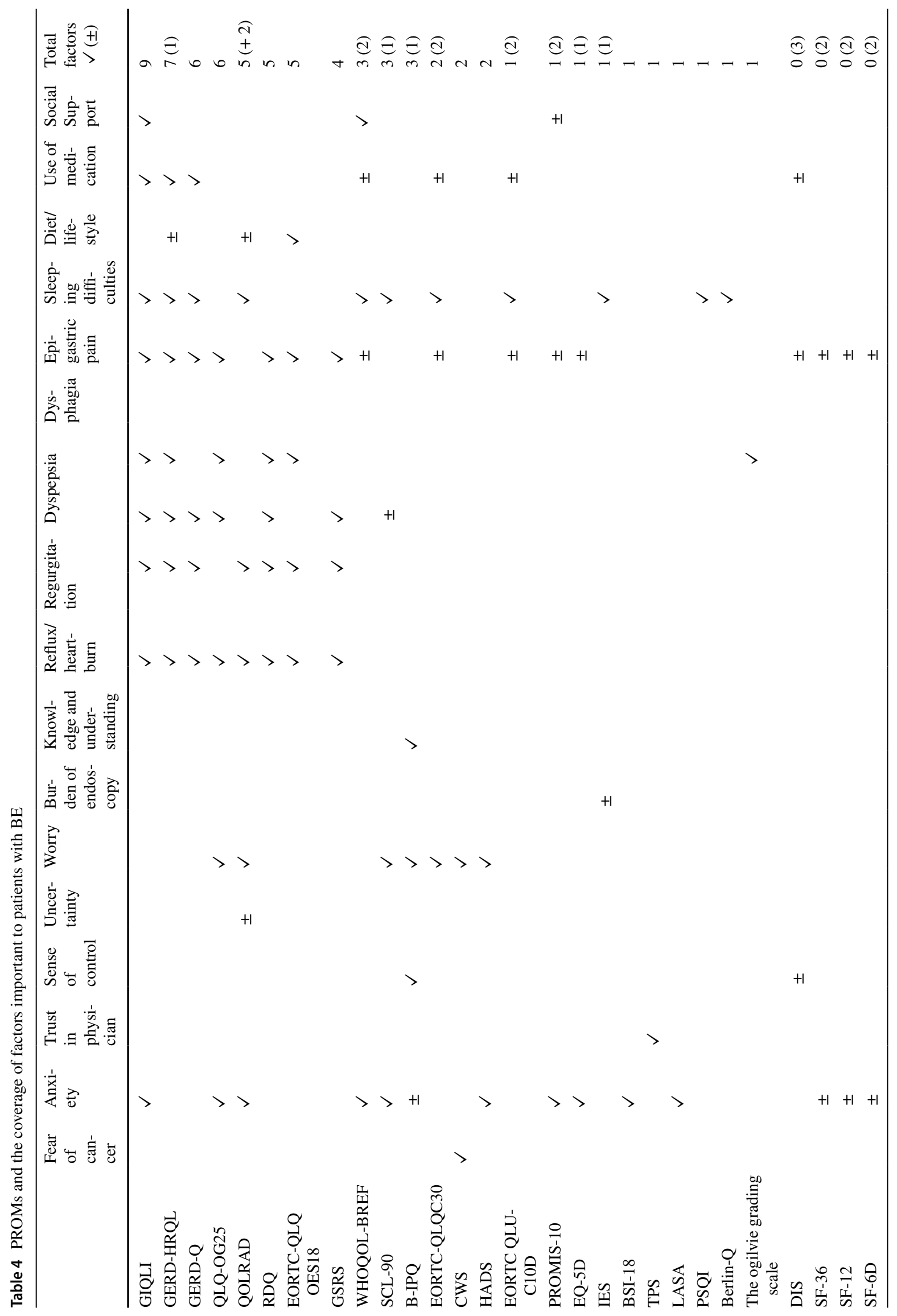

Springer 


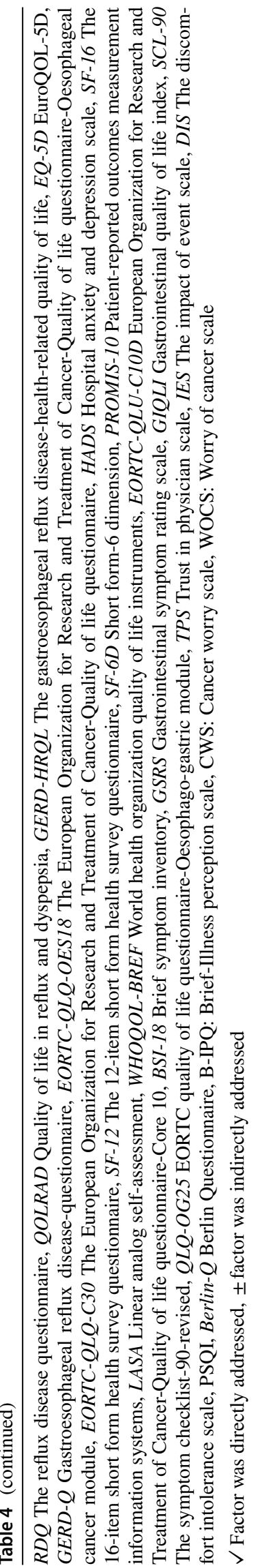

an independent extraction of potential factors was performed by two researchers.

In conclusion, none of the studies measuring HRQoL in BE patients sufficiently reflected the perceptions of HRQoL in BE patients. For the selection of PROMs, we encourage physicians and researchers measuring HRQoL to choose their PRO from a patient perspective and not strictly based on relevance according to health professionals' definitions. Using PROMs that are more patient-centered will enhance knowledge of the true impact of surveillance and endoscopic treatment on the (perceived) functioning of BE patients.

Author contributions SRN: Made a significant contribution to the work reported, on acquisition of data, analysis, interpretation, and critically reviewed the article. PTN: Made a significant contribution to the work reported on study design and critically reviewed the article. WLC: Made a significant contribution to the work reported, by critically reviewing the article. EJS: Made a significant contribution to the work reported on study design and critically reviewed the article.

Funding This work was supported by a grant from the Catharina Research Foundation. This organization was not involved in planning, performing the study, or preparing the manuscript.

Data availability The data that support the findings of this study are available from the corresponding author upon reasonable request.

Code availability The primary methodology and inclusion criteria were published in a protocol in the PROSPERO database under registration number CRD42021224231.

\section{Declarations}

Conflict of interest The authors declare no commercial, financial, or potential personal conflicts of interest.

Ethical approval Ethical approval was not required because the review was a secondary analysis of anonymized data that were already published.

Open Access This article is licensed under a Creative Commons Attribution 4.0 International License, which permits use, sharing, adaptation, distribution and reproduction in any medium or format, as long as you give appropriate credit to the original author(s) and the source, provide a link to the Creative Commons licence, and indicate if changes were made. The images or other third party material in this article are included in the article's Creative Commons licence, unless indicated otherwise in a credit line to the material. If material is not included in the article's Creative Commons licence and your intended use is not permitted by statutory regulation or exceeds the permitted use, you will need to obtain permission directly from the copyright holder. To view a copy of this licence, visit http://creativecommons.org/licenses/by/4.0/.

\section{References}

1. Barrett, N. R. (1950). Chronic peptic ulcer of the oesophagus and "oesophagitis." British Journal of Surgery, 38, 175-182. 
2. Allison, P. R., \& Johnstone, A. S. (1953). The oesphagus lined with gastric mucous membrane. Thorax, 8, 87-101.

3. Yousef, F., Cardwell, C., Galway, K., et al. (2008). The incidence of esophageal cancer and high-grade dysplasia in Barrett's Esophagus: A systematic review and meta-analysis. American Journal of Epidemiology, 168(3), 237-249.

4. Desai, T. K., Krishnan, K., Samala, N., et al. (2012). The incidence of oesophageal adenocarcinoma in non-dysplastic Barrett's oesophagus: A meta-analysis. Gut, 61, 970-976.

5. Caygill, C. P., Royston, C., Charlett, A., et al. (2012). Mortality in Barrett's esophagus: Three decades of experience at a single center. Endoscopy, 44, 892-898.

6. Solaymani-Dodaran, M., Card, T. R., \& West, J. (2013). Causespecific mortality of people with Barrett's Esophagus compared with the general population: A population-based cohort study. Gastroenterology, 144, 1375-1383.

7. Sikkema, M., de Jonge, P. J. F., Steyerberg, E. W., \& Kuipers, E. J. (2010). Risk of esophageal adenocarcinoma and mortality in patients with Barrett's Esophagus: A systematic review and metaanalysis. Clinical Gastroenterology and Hepatology, 8, 235-244.

8. Britton, J., Keld, R., Prasad, N., Hamdy, S., McLaughlin, J., \& Ang, Y. (2018). Effect of diagnosis, surveillance, and treatment of Barrett's Esophagus on health-related quality of life. The Lancet Gastroenterology Hepatology, 3(1), 57-65.

9. Crockett, S. D., Lippmann, Q. K., Dellon, E. S., et al. (2009). Health-related quality of life in patients with Barrett's Esophagus: A systematic review. Clinical Gastroenterology and Hepatology, 7(6), 613-623.

10. Testa, M. A., \& Simonson, D. C. (1996). Assessment of quality-of-life outcomes. New England Journal of Medicine, 334, 835-840.

11. Liberati, A., Altman, D. G., Tetzlaff, J., et al. (2009). The PRISMA statement for reporting systematic reviews and meta-analyses of studies that evaluate health care interventions: Explanation and elaboration. PLoS Medicine, 6, e1000100.

12. WHOQOL-Group. (1995). The world health organization quality of life assessment (WHOQOL): Position paper from the world health organization. Social Science and Medicine, 41, 1403-1409.

13. OCEBM Levels of Evidence Working Group*. "The Oxford Levels of Evidence 2". Oxford Centre for Evidence-Based Medicine. https://www.cebm.ox.ac.uk/resources/levels-of-evidence/ocebmlevels-of-evidence.

14. Critical Appraisal Skills Programme. (CASP). CASP Checklists. Oxford: CASP, 2014. https://casp-uk.net/wp-content/uploads/ 2018/03/CASP-Qualitative-Checklist-2018_fillable_form.pdf

15. Terwee, C. B., van der Wees, P. J., en Sandra Beurskens, S., namens het NFU expertisenetwerk Patient-reported outcomes. (2015). Handreiking voor de selectie van PROs en PROMs; Utrecht: Nederlandse Federatie van Universitair Medische Centra (NFU).

16. Kruijshaar, M. E., Kerkhof, M., Siersema, P. D., Steyerberg, E. W., Homs, M. Y., Essink-Bot, M. L., \& CYBAR Study Group. (2006). The burden of upper gastrointestinal endoscopy in patients with Barrett's Esophagus. Endoscopy, 38(9), 873-878.

17. Han, S., Yadlapati, R., Simon, V., Ezekwe, E., Early, D. S., Kushnir, V., Hollander, T., Brauer, B. C., Hammad, H., Edmundowicz, S. A., Wood, M., Shaheen, N. J., Muthusamy, R. V., Komanduri, S., \& Wani, S. (2019). Dysplasia severity is associated with poor quality of life in patients with Barrett's Esophagus referred for endoscopic eradication therapy. Disease of Esophagus. https:// doi.org/10.1093/dote/doy086

18. Miller, R. C., Atherton, P. J., Kabat, B. F., Fredericksen, M. B., Geno, D. M., Deschamps, C., Jatoi, A., Sloan, J. A., \& Romero, Y. (2010). Marital status and quality of life in patients with esophageal cancer or Barrett's Esophagus: The mayo clinic esophageal adenocarcinoma and Barrett's esophagus registry study. Digestive Disease and Science, 55(10), 2860-2868.

19. Lippmann, Q. K., Crockett, S. D., Dellon, E. S., \& Shaheen, N. J. (2009). Quality of life in GERD and Barrett's Esophagus is related to gender and manifestation of disease. The American Journal of Gastroenterology, 104(11), 2695-2703.

20. Eloubeidi, M. A., \& Provenzale, D. (2000). Health-related quality of life and severity of symptoms in patients with Barrett's Esophagus and gastroesophageal reflux disease patients without Barrett's esophagus. The American Journal of Gastroenterology, 95(8), 1881-1887.

21. Rosmolen, W. D., Nieuwkerk, P. T., Pouw, R. E., van Berge Henegouwen, M. I., Bergman, J. J., \& Sprangers, M. A. (2017). Quality of life and fear of cancer recurrence after endoscopic treatment for early Barrett's neoplasia: A prospective study. Disease of Esophagus, 30(3), 1-9.

22. Rosmolen, W. D., Boer, K. R., de Leeuw, R. J., Gamel, C. J., van Berge Henegouwen, M. I., Bergman, J. J., \& Sprangers, M. A. (2010). Quality of life and fear of cancer recurrence after endoscopic and surgical treatment for early neoplasia in Barrett's Esophagus. Endoscopy, 42(7), 525-531.

23. Rosmolen, W. D., Phoa, N. K. Y. N., Nieuwkerk, P. T., Pouw, R. E., Weusten, B. L. A. M., Bisschops, R., Schoon, E. J., Sprangers, M. A. G., \& Bergman, J. J. G. H. M. (2019). Impact of ablation of Barrett's Esophagus with low-grade dysplasia on patients' illness perception and quality of life: A multicenter randomized trial. Gastrointestinal Endoscopy, 90(2), 215-221.

24. Gerson, L. B., Ullah, N., Hastie, T., \& Goldstein, M. K. (2007). Does cancer risk affect health-related quality of life in patients with Barrett's Esophagus? Gastrointestinal Endoscopy, 65(1), $16-25$.

25. Kulig, M., Leodolter, A., Vieth, M., Schulte, E., Jaspersen, D., Labenz, J., Lind, T., Meyer-Sabellek, W., Malfertheiner, P., Stolte, M., \& Willich, S. N. (2003). Quality of life in relation to symptoms in patients with gastro-oesophageal reflux disease-An analysis based on the ProGERD initiative. Alimentary Pharmacology and Therapeutics, 18(8), 767-776.

26. Vela, M. F., Kramer, J. R., Richardson, P. A., Dodge, R., \& ElSerag, H. B. (2013). Poor sleep quality and obstructive sleep apnea in patients with GERD and Barrett's Esophagus. Neurogastroenterology and Motility: The Official Journal of the European Gastrointestinal Motility Society, 26(3), 346-352.

27. Bulamu, N. B., Chen, G., Ratcliffe, J., Schloite, A., Bright, T., \& Watson, D. I. (2019). Health-related quality of life associated with Barrett's Esophagus and cancer. World Journal of Surgery, 43(6), $1554-1562$.

28. Chang, C. Y., Lee, L. J., Wang, J. D., Lee, C. T., Tai, C. M., Tang, T. Q., \& Lin, J. T. (2016). Health-related quality of life in patients with Barrett's Esophagus. Health and Quality of Life Outcomes, 14(1), 158.

29. Lee, S. W., Lien, H. C., Chang, C. S., Ko, C. W., Tung, C. F., \& Yeh, H. Z. (2017). Health-related quality of life of subjects with Barrett's Esophagus in a Chinese population. PLoS ONE, 12(12), e0190201.

30. Schembre, D., Arai, A., Levy, S., Farrell-Ross, M., \& Low, D. (2010). Quality of life after esophagectomy and endoscopic therapy for Barrett's Esophagus with dysplasia. Disease of Esophagus, 23(6), 458-464.

31. Shaheen, N. J., Peery, A. F., Hawes, R. H., Rothstein, R. I., Spechler, S. J., Galanko, J. A., Campbell, M., Carr, C., Fowler, B., Walsh, J., Siddiqui, A. A., Infantolino, A., Wolfsen, H. C., \& AIM Dysplasia Trial Investigators. (2010). Quality of life following radiofrequency ablation of dysplastic Barrett's Esophagus. Endoscopy, 42(10), 790-799.

32. van der Ende-van Loon, M. C. M., Rosmolen, W. D., Houterman, S., Schoon, E. J., \& Curvers, W. L. (2018). Cancer risk perception 
in relation to associated symptoms in Barrett's patients: A cross sectional study on quality of life. United European Gastroenterology Journal, 6(9), 1316-1322.

33. Gerson, L. B., Ullah, N., Hastie, T., Triadafilopoulos, G., \& Goldstein, M. (2005). Patient-derived health state utilities for gastroesophageal reflux disease. The American Journal of Gastroenterology, 100(3), 524-533.

34. Crockett, S. D., Lipkus, I. M., Bright, S. D., Sampliner, R. E., Wang, K. K., Boolchand, V., Lutzke, L. S., \& Shaheen, N. J. (2012). Overutilization of endoscopic surveillance in nondysplastic Barrett's Esophagus: A multicenter study. Gastrointestinal Endoscopy, 75(1), 23-31.

35. Peerally, M. F., Bhandari, P., Ragunath, K., Barr, H., Stokes, C., Haidry, R., Lovat, L., Smart, H., Harrison, R., Smith, K., Morris, T., \& de Caestecker, J. S. (2019). Radiofrequency ablation compared with argon plasma coagulation after endoscopic resection of high-grade dysplasia or stage T1 adenocarcinoma in Barrett's Esophagus: A randomized pilot study (BRIDE). Gastrointestinal Endoscopy, 89(4), 680-689.

36. Baldaque-Silva, F., Vieth, M., Debel, M., Håkanson, B., Thorell, A., Lunet, N., Song, H., Mascarenhas Saraiva, M., Pereira, G., Lundell, L., \& Marschall, H. U. (2017). Impact of gastroesophageal reflux control through tailored proton pump inhibition therapy or fundoplication in patients with Barrett's Esophagus. World Journal of Gastroenterology, 23(17), 3174-3183.

37. Hauge, T., Franco-Lie, I., Løberg, E. M., Hauge, T., \& Johnson, E. (2020). Outcome after endoscopic treatment for dysplasia and superficial esophageal cancer - A cohort study. Scandinavian Journal of Gastroenterology, 55(9), 1132-1138.

38. Britton, J., Taxiarchi, P., Martin, G., Willert, R., Horne, M., Hamdy, S., McLaughlin, J., \& Ang, Y. (2020). Comparative quantitative survey of patient experience in Barrett's oesophagus and other gastrointestinal disorders. BMJ Open Gastroenterology, 7(1), e000357.

39. Reddy, C. A., Tavakkoli, A., Chen, V. L., Korsnes, S., Bedi, A. O., Carrott, P. W., Chang, A. C., Lagisetty, K. H., Kwon, R. S., Elmunzer, B. J., Orringer, M. B., Piraka, C., Prabhu, A., Reddy, R. M., Wamsteker, E., \& Rubenstein, J. H. (2020). Long-term quality of life following endoscopic therapy compared to esophagectomy for neoplastic Barrett's Esophagus. Digestive Disease of Sciences. https://doi.org/10.1007/s10620-020-06377-1

40. Schwameis, K., Zehetner, J., Green, K. M., \& DeMeester, S. R. (2020). Workload, recurrence, quality of life and long-term efficacy of endoscopic therapy for high-grade dysplasia and intramucosal esophageal adenocarcinoma. Annals of Surgery, 271(4), 701-708.

41. Essink-Bot, M. L., Kruijshaar, M. E., Bac, D. J., Wismans, P. J., ter Borg, F., Steyerberg, E. W., \& Siersema, P. D. (2007). Different perceptions of the burden of upper GI endoscopy: An empirical study in three patient groups. Quality of Life Research, 16(8), 1309-1318.

42. Cooper, S. C., El-agib, A., Dar, S., Mohammed, I., Nightingale, P., Murray, I. A., Cooper, B. T., \& Trudgill, N. J. (2009). Endoscopic surveillance for Barrett's oesophagus: The patients' perspective. European Journal of Gastroenterology Hepatology, 21(8), 850-854.

43. Britton, J., Hamdy, S., McLaughlin, J., Horne, M., \& Ang, Y. (2019). Barrett's oesophagus: A qualitative study of patient burden, care delivery experience and follow-up needs. Health Expectation, 22(1), 21-33.

44. Arney, J., Hinojosa-Lindsey, M., Street, R. L., Jr., Hou, J., ElSerag, H. B., \& Naik, A. D. (2014). Patient experiences with surveillance endoscopy: A qualitative study. Digestive Diseases and Sciences, 59(7), 1378-1385.

45. Griffiths, H., \& Davies, R. (2011). Understanding Barrett's columnar lined oesophagus from the patients' perspective: Qualitative analysis of semistructured interviews with patients. Frontline Gastroenterology, 2(3), 168-175.

46. van der Ende-van Loon MCM, Brouwers M, Munnik S, et al. (2021) Factors influencing health related quality of life in patients with Barrett's Esophagus: A qualitative focus group study. European Journal Gastroenterology and Hepatology. Online ahead of print.

47. Tavankit, S., Madhusudhan, R. S., \& Prashanthi, N. T. (2018). Endoscopic therapy for Barrett's esophagus and early esophageal cancer: Where do we go from here? World Journal of Gastrointestinal Endoscopy, 10(9), 165-174.

48. Crossnohere, N. L., Brundage, M., Calvert, M. J., King, M., Reeve, B. B., Thorner, E., Wu, A. W., \& Snyder, C. (2020). International guidance on the selection of patient-reported outcome measures in clinical trials: A review. Quality of Life Research, 30(1), 21-40.

49. Cella, D., Yount, S., Rothrock, N., Gershon, R., Cook, K., Reeve, B., Ader, D., Fries, J. F., Bruce, B., \& Rose, M. (2007). The patient-reported outcomes measurement information system (PROMIS): Progress of an NIH roadmap cooperative group during its first two years. Medical Care, 45, S3-S11.

50. Witter, J. P. (2016). Introduction: PROMIS a first look across diseases. Journal of Clinical Epidemiology, 73, 87-88.

51. PROMIS. Patient Reported Outcomes Measurement Information System 2018. http://www.healthmeasures.net/explore-measu rement-systems/promis

Publisher's Note Springer Nature remains neutral with regard to jurisdictional claims in published maps and institutional affiliations. 